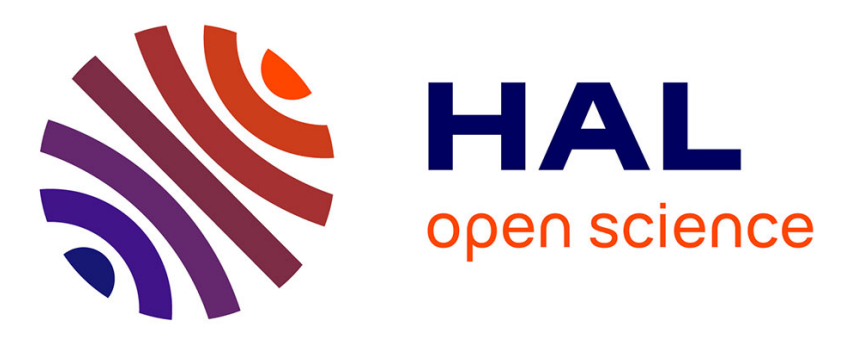

\title{
Analytical Model of Magnet Eddy-Current Volume Losses in Multi-phase PM Machines with Concentrated Winding
}

\author{
Bassel Aslan, Eric Semail, Jerôme Legranger
}

\section{- To cite this version:}

Bassel Aslan, Eric Semail, Jerôme Legranger. Analytical Model of Magnet Eddy-Current Volume Losses in Multi-phase PM Machines with Concentrated Winding. ECCE'12, IEEE Energy Conversion Congress, Sep 2012, United States. pp 3371-3378, 10.1109/ECCE.2012.6342330 hal-00817557

\section{HAL Id: hal-00817557 https://hal.science/hal-00817557}

Submitted on 25 Apr 2013

HAL is a multi-disciplinary open access archive for the deposit and dissemination of scientific research documents, whether they are published or not. The documents may come from teaching and research institutions in France or abroad, or from public or private research centers.
L'archive ouverte pluridisciplinaire HAL, est destinée au dépôt et à la diffusion de documents scientifiques de niveau recherche, publiés ou non, émanant des établissements d'enseignement et de recherche français ou étrangers, des laboratoires publics ou privés. 


\section{Analytical Model of Magnet Eddy-Current Volume Losses in Multi-phase PM Machines with Concentrated Winding}

\author{
Bassel Aslan ${ }^{(1,2)}$, Eric Semail ${ }^{(1)}$ \\ ${ }^{(1)}$ Arts et Metiers Paristech - L2EP \\ 8 Bd Louis XIV, 59046 Lille France \\ bassel.aslan-1@etudiants.ensam.eu
}

\author{
Jerome Legranger ${ }^{(2)}$ \\ ${ }^{(2)}$ VALEO-EEM \\ 2 rue André Boulle, 94000 Créteil France
}

\begin{abstract}
- this paper studies magnet eddy-current losses in permanent magnet (PM) machines with concentrated winding. First of all, space harmonics of magnetomotive force (MMF) and their influence on magnet losses in electrical machines are investigated. Secondly, analytical model of magnet volume losses is developed by studying the interaction between MMF harmonics wavelengths and magnet pole dimensions. Different cases of this interaction are studied according to the ratio between each harmonic wavelength and magnet pole width (following flux density variation). Then various losses sub-models are deduced. Finally, using this analytical model, magnet volume losses for many slots/poles combinations of 3,5 , and 7 phase machines with concentrated winding are compared. This comparison leads to classify combinations into different families depending on their magnet losses level. Besides, in order to validate the theoretical study, Finite Element models are built and simulation results are compared with analytical calculations.
\end{abstract}

Keywords-Traction, Concentrated Winding, EddyCurrent, Volume Magnet Losses, Multiphase Machine, Automotive, MMF, Spatial Harmonics

\section{INTRODUCTION}

Nowadays Permanent Magnet motors (PM) with fractional-slot concentrated winding are becoming a preferred choice for automotive applications, due to their high torque/volume ratio, high efficiency, and simple structure which means easy manufacturing, maintenance, and recycling [1]. The main problem with machines of fractional-slot concentrated winding is the existence of parasitic effects which in certain cases might be unbearable because of unbalanced mechanical structure or high eddy-current rotor losses. Therefore, many researches tried to classify this kind of machines in order to avoid bad choice of Slots/Poles combination [2]-[3].

Rotor permanent magnets cannot be heavily segmented as it is the case for electrical steel. Hence, rotor magnets eddy-current losses are one of the most dangerous effects in the machines with concentrated winding, mainly in automotive applications where high speed is often needed in flux weakening operation. These losses can extremely heat magnets until causing permanent demagnetization which leads to full breakdown in the machine functionality. Obviously, machines used in application of relatively high speed must have low magnet volume losses. Some studies have been done regarding the effect of MMF asynchronous spatial harmonics on rotor losses in synchronous machines [4]-[5]. The results show that some slots/poles combinations of concentrated winding machines create undesired MMF spatial spectrum of harmonics which can induce high level of rotor losses. Most of these studies are based on analytical resolution of Maxwell equations (calculate magnetic vector potential $A$ ) in order to calculate eddy-current magnet losses [6]-[7]. As a result, complicated equations which generally depend on the specific concerned structure will appear. Besides, the precision of results is depending on the degree of validity of assumptions used for the resolution of the equations. Another calculation point of view is presented in few papers depending on traditional eddy-current elementary paths division [8]-[9]. Thus, simple models of magnet volume losses are deduced but always without taking into account the various MMF spatial harmonic wavelengths that result from concentrated winding structure.

Therefore, by considering the same kind of calculation used in [8]-[9] the present paper is concerned by the following investigation: how wavelengths of MMF spatial harmonics in the air gap interact with rotor magnet pole dimensions causing different levels of magnet losses?

Generally, accurate value of magnet losses is linked to accurate calculation of flux densities resulting from MMF harmonics. Since flux density varies with the studied magnetic structure, the objective of the paper is not to determine precisely the amount of magnet losses for each particular machine, but rather to develop a tool which ensures a precise magnet losses comparison between generic machines taking into account their winding topologies.

The first part of this paper explains the different natures of MMF harmonics in the air gap depending on their wavelengths (harmonics, sub-harmonics) or their relative spatial propagation speeds according to the rotor. In the second part analytical formulations of magnet volume losses are developed considering various models of eddy-current paths in the magnet pole resulting from several ways of harmonic-magnet interaction. Hence, for all MMF harmonics orders, 
different sub-models of magnet volume losses are built in order to represent different shapes of induced eddycurrent circuits.

The third part of paper uses the developed analytical model in order to compare different Slots/Poles combinations of 3, 5, and 7-phase machines according to their level of magnet volume losses. This comparison is done considering only combinations winding topologies (MMF harmonics) and magnet pole dimensions, while the inclusion of structures with 3, 5 and 7 phases offers more possible configurations to be compared.

Finally, Finite Elements models for some combinations are built in order to validate the analytical comparison. Then, some configurations are proposed to be preferred candidates of practical machines with low magnet volume losses.

\section{Magnet losses theory}

In classical integral-slot winding machines, MMF has $p$ regular repeated forms and its parasitic spatial harmonics in the air gap are multiples of the fundamental one.

$$
\begin{aligned}
& \lambda_{v}=\frac{2 \cdot \pi \cdot R_{\text {rotor }}}{v} \\
& v=(2 k+1) p \Rightarrow \lambda_{v}=\frac{\lambda_{\text {fund }}}{2 k+1} \\
& \lambda_{\text {fund }}=\lambda_{p}, k \in N, R_{\text {rotor }}: \text { radius of rotor } \\
& p: \text { number of pole pairs, } v \text { :harmonic order } \\
& \lambda_{v}: \text { wavelength of the harmonic } v
\end{aligned}
$$

However, in the case of fractional-slot concentrated winding, MMF can contain parasitic spatial harmonics with various orders which may be close to the fundamental or even lower (called subharmonics) Fig. 1 (a) [10]:

- Harmonics close to fundamental

$$
p<v<2 p \Leftrightarrow \frac{\lambda_{p}}{2}<\lambda_{v}<\lambda_{p}
$$

- Sub-harmonics

$$
v<p \Leftrightarrow \lambda_{v}>\lambda_{p}
$$

The fact that concentrated winding machines are accompanied with such MMF harmonics nominates these harmonics as the main suspect of causing high magnet losses.

MMF parasitic harmonics rotate in the air gap with different speeds $\left(V_{v}\right)$ inducing currents in rotor magnet blocks and causing magnet losses [5]. Magnet flux density variation resulting from stator teeth can also produce certain amount of magnet losses (called usually slotting effect). However, this kind of losses depends mainly on the structure (teeth-slots shape) and generally it has less importance at high speeds, where crossing magnetic flux between stator and rotor is highly reduced by flux weakening procedure. Thus, in this paper only losses caused by MMF parasitic harmonics are considered.

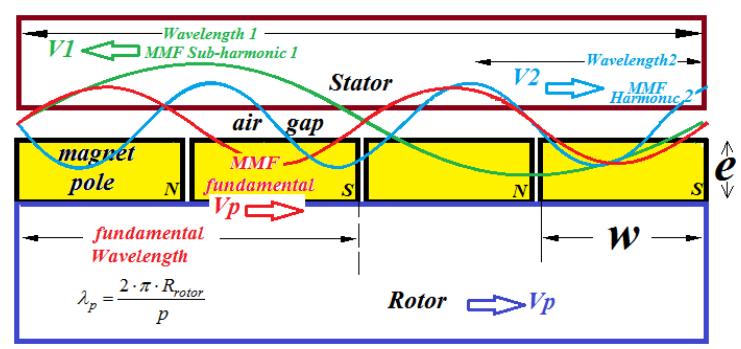

(a): representative example of MMF space harmonics in the air gap of surface-mounted permanent magnet radial flux machine

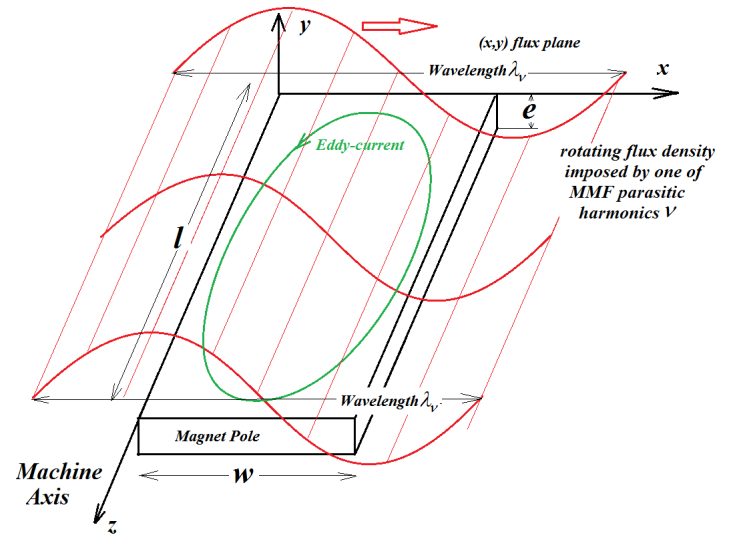

(b): Eddy-currents induced in a magnet pole by one of MMF parasitic harmonics

Figure 1. MMF space harmonics applied on magnet poles in PM machines

Each MMF harmonic has three characteristics which can mainly affect losses level:

$>$ the amplitude which decides the related magnetic flux density in the air gap;

$>$ the relative speed in the air gap $\left(V_{v}\right)_{r}$ with respect to the rotor;

$>$ the wavelength.

MMF fundamental harmonic advances in the air gap with a zero relative $\operatorname{speed}\left(V_{p}=V_{\text {rotor }}\right)$, while other parasitic harmonics have different relative speeds $\left(V_{v}\right)_{r}$. These moving MMF harmonics create rotating flux density distribution of different wavelengths in the air gap (see Fig. 1).

Consequently, by considering a reference point in rotor magnet blocks, the frequency of magnetic flux density resulting from the rotating harmonic $v$ can be calculated [4]:

$$
\begin{aligned}
& \left(V_{v}\right)_{r}=\left|V_{p}-\operatorname{sgn} \cdot V_{v}\right|=V_{v}\left|\frac{v}{p}-\operatorname{sgn}\right| \\
& f_{B V}=\frac{\left(V_{v}\right)_{r}}{\lambda_{v}}=f_{\text {rotor }} p\left|\frac{v}{p}-\operatorname{sgn}\right|
\end{aligned}
$$


$f_{\text {rotor }}:$ rotor speed $($ tunr $/ \mathrm{sec})$

sgn :rotating direction of harmonic $v$

In Surface-Mounted PM machine (SPM) the same rotating flux density sinusoidal distributions imposed by MMF harmonics in the air gap are applied directly on magnet blocks. Consequently, these blocks see almost the same distribution wavelengths as in the air gap Fig. 1 (b). While, in the case of Interior PM Machine (IPM) flux concentration makes magnet blocks see flux rotating distributions with wavelengths equal to those of the air gap multiplied by certain concentration ratio.

This paper is interested in studying magnet losses caused by the interaction between flux density wavelengths $\lambda_{v}$ and magnet pole dimensions $(l, w, e)$ Fig. 1 (b). Hence, magnet poles are considered as electrically isolated blocks, which is generally true in electrical machines.

\section{Analytical model of magnet volume losses}

Magnets in PM electrical machines are the only big not segmented conductors in the rotor. This makes them perfect targets of MMF parasitic harmonics which induce long circuits of eddy-currents in them.

In this paragraph various eddy-currents paths in magnets are proposed according to MMF-magnet interaction. Joule losses caused by these currents are then calculated. In order to simplify losses model calculations some assumptions are imposed:

- Magnet losses resulting from hysteresis and slotting effect are not considered in this analytical model, but only magnet losses generated by MMF parasitic harmonics are considered. Obviously, at high speed where much more magnet losses can be generated, slotting effect becomes less important due to flux weakening procedure.

- Magnet losses are the sum of losses caused by each sinusoidal rotating distribution of flux density $B_{v}$ with a wavelength $\lambda_{v}$ resulting from the MMF parasitic harmonic of the order $v$.

- Flux density variation according to magnet thickness $(e)$ and length $(l)$ is neglected.

- Skin effect phenomenon is not taken into account.

Finally, in order to make a fair comparison, magnet volume losses $\quad P_{v o l}=($ Lost Power $/$ Volume $)$ are calculated in the model.

The configuration of paths taken by eddy-currents in magnet block depends on the ratio between the wavelength $\lambda_{v}$ of MMF parasitic harmonic (which induces these currents) and magnet block width $w$. This variation of paths is the result of phase differences between induced current densities along the magnet block width.

The different situations of interaction between magnet pole width and MMF harmonic wavelength are illustrated in Fig 2.
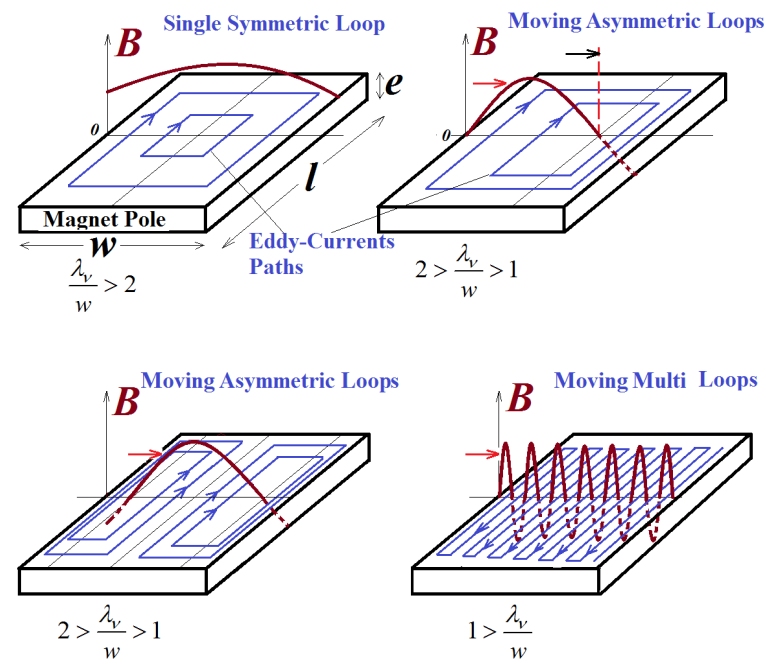

Figure 2. different paths of eddy-current circuits according MMF wavelength and magnet width

In order to validate the supposed current paths configurations, 2D finite elements models similar to SPM machines are built. In these models, MMF with a single dominant constant harmonic is created in the air gap, while relative speed of magnets according to this harmonic is ensured due to constant rotor velocity. Using these models, magnets eddy-current densities distribution is calculated for different ranges of $\lambda_{v} / w$ and the results are shown in Fig. 3.

- If $\lambda_{v} / w>2$, induced current densities cross the magnet plan (width $w$, thickness $e$ ) with a phase shift lower than $180^{\circ}$. Nevertheless, the fact that magnet blocks are electrically isolated forces the induced current to circulate back forming a single symmetric eddy-current loop as it can be seen in Fig. 3 (a).

- When the ratio $\lambda_{v} / w$ starts to be smaller than 2 , eddy-current paths take a form of asymmetric variable loops where their centers move along the width of magnet pole with the same relative speed as the harmonic $v$ (Fig. 2). This variable situation is a result of phase shift higher than $180^{\circ}$ in induced current densities along the magnet width (see Fig. 3 (b)).

- Finally, while magnet pole width is becoming much longer than MMF wavelength $\lambda_{v} / w<<1$, new variable moving eddy-current loops will be generated (Fig. 3(c)). Since every added current loop generates locally the same amount of Joule losses as the other loops, the influence of magnet width on 
total magnet volume losses becomes negligible when $\lambda_{v} / w<<1$.

Considering the previous situations of eddycurrent loops, elementary current paths which correspond to the geometry of symmetric and asymmetric loops are created for different instants of times as it can be noticed in Fig. 4.
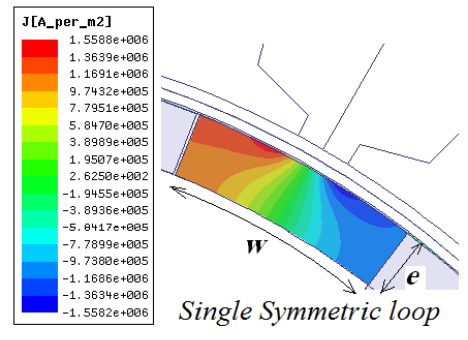

Single Symmetric loop

(a): $\lambda_{v} / w>2$
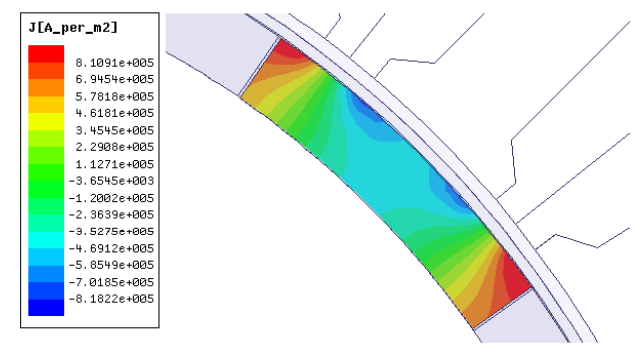

Moving Asymmetric Loops

(b): $2>\lambda_{v} / w>1$
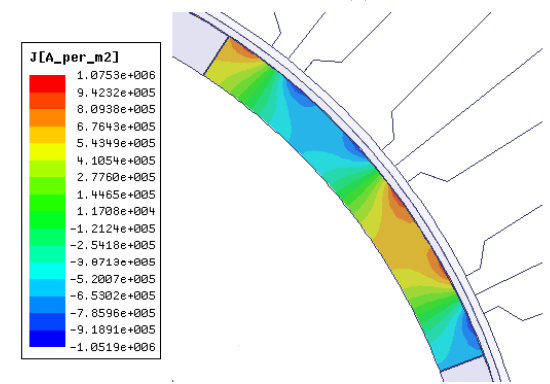

Moving Multi Loops

(c): $1>\lambda_{v} / w$

Figure 3. 2D finite elements model of eddy-current density distribution in magnets

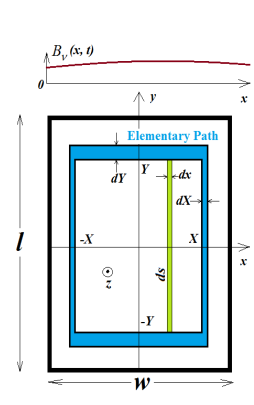

$$
\frac{\lambda_{v}}{w}>2
$$

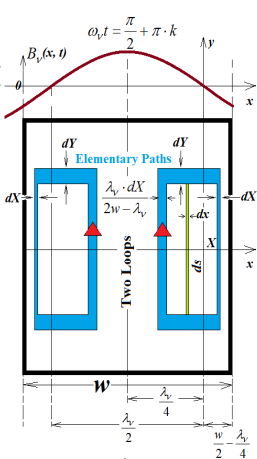

$$
2>\frac{\lambda_{v}}{w}>1
$$

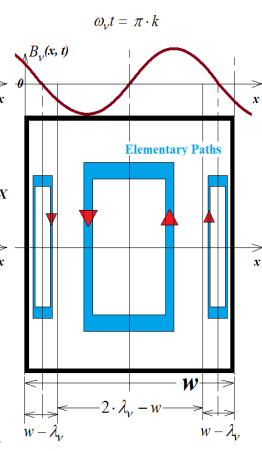

$1>\frac{\lambda_{v}}{w}$

Figure 4. elementary eddy-current paths used to develop the analytical model
Magnetic flux captured by each elementary eddycurrent path can be written (the elementary path is identified by $X)$ :

$\Phi_{e}=\int_{x} B_{v}(x, t) \cdot d s$ :

$B_{v}(x, t)=B_{v} \cdot \sin \left(\omega_{v} t+\frac{2 \pi}{\lambda_{v}} x\right)$

$\Phi_{e}$ : magnetic flux through elementary path

$B_{v}:$ flux density amplitude of MMF harmonic $v$

$\omega_{v}:$ flux density pulsation in magnets $=2 \cdot \pi \cdot f_{B v}$

Then, mean value of Joule losses in every elementary current path $\left(d P_{e}\right)$ can be calculated:

$d P_{e}=\left\langle\frac{\left(\frac{\partial \Phi_{e}(X, t)}{\partial t}\right)^{2}}{R_{e}}\right\rangle$

$R_{e}(X)$ : electrical resistance of elementary current path Finally, global magnet volume losses $\left(\left(P_{v o l}\right)_{V}\right)$ caused by an MMF parasitic harmonic $v$ are deduced in various cases of eddy-current configuration $(a, b$, and $c$ in Fig. 3) represented by various ranges of $\lambda_{v} / w$ :

$$
\begin{aligned}
& \int_{X} d P_{e} \\
& \left(P_{\text {vol }}\right)_{V}=\frac{\text { all elementary paths }}{\text { magnet pole volume }} \Rightarrow \\
& {\left[\left(P_{v o l}\right)_{v}\right]=\left[\begin{array}{l}
\text { if } \frac{\lambda_{v}}{w^{\prime}}>2 \\
\frac{w^{\prime} \cdot\left[\left(P_{v o l}\left(w^{\prime}\right)\right)_{v}\right]_{a}+n \cdot \frac{3}{2} \cdot \lambda_{v} \cdot\left[\left(P_{v o l}\right)_{v}\right]_{d}}{w} \\
\frac{w^{\prime} \cdot\left[\left(P_{v o l}\left(w^{\prime}\right)\right)_{v}\right]_{b}+n \cdot \frac{3}{2} \cdot \lambda_{v} \cdot\left[\left(P_{v o l}\right)_{v}\right]_{d}}{w} \\
\frac{\lambda_{v}}{w^{\prime} \cdot\left[\left(P_{v o l}\left(w^{\prime}\right)\right)_{v}\right]_{c}+n \cdot \frac{3}{2} \cdot \lambda_{v} \cdot\left[\left(P_{v o l}\right)_{v}\right]_{d}} \\
w
\end{array}\right.} \\
& {\left[\left(P_{v o l}\right)_{v}\right]_{a}=\frac{\alpha^{2} B_{v}{ }^{2} \omega_{v}^{2}}{2 . \pi^{2} \rho\left(\alpha^{2}+1\right)} \times} \\
& {\left[\frac{\lambda_{v}{ }^{2}}{16}+\frac{\lambda_{v}{ }^{4}}{32 \cdot \pi^{2} w^{2}}\left(1-\cos \left(\frac{2 \pi}{\lambda_{v}} w\right)\right)-\frac{\lambda_{v}{ }^{3}}{16 \cdot \pi \cdot w} \sin \left(\frac{2 \pi}{\lambda_{v}} w\right)\right]}
\end{aligned}
$$




$$
\begin{aligned}
& {\left[\left(P_{v o l}\right)_{V}\right]_{b}=\frac{\left(\left[\left(P_{v o l}\right)_{V}\right]_{b}\right)_{S 1}+\left(\left[\left(P_{v o l}\right)_{V}\right]_{b}\right)_{S 2}}{2}:} \\
& \left(\left[\left(P_{v o l}\right)_{v}\right]_{b}\right)_{S 1}=2 \times\left[\left(P_{v o l}\right)_{v}\right]_{a} \\
& \left(\left[\left(P_{v o l}\right)_{v}\right]_{b}\right)_{S 2}=\frac{\frac{4 \cdot w^{2} \cdot \alpha^{2}}{\left(2 \cdot w-\lambda_{v}\right) \cdot \lambda_{v}} \cdot B_{v}{ }^{2} \cdot \omega_{v}{ }^{2}}{2 \cdot \rho \cdot \pi^{2} \cdot\left(1+\frac{4 \cdot w^{2} \cdot \alpha^{2}}{\left(2 \cdot w-\lambda_{v}\right) \cdot \lambda_{v}}\right)} \times \\
& {\left[\frac{\left(2 \cdot w-\lambda_{v}\right) \cdot \lambda_{v}{ }^{3}}{16 \cdot w^{2}} \cdot\left(1+\frac{2}{\pi^{2}}+\frac{2 \cdot \lambda_{v}{ }^{2}}{\pi^{2}} \cdot\left(\frac{1}{w^{2}}-\frac{1}{\left(w-\lambda_{v}\right)^{2}}\right)\right)\right.} \\
& +\frac{\lambda_{v}{ }^{4}}{16 \cdot \pi \cdot w^{2}} \cdot \sin \left(\frac{2 \cdot w \cdot \pi}{\lambda_{v}}\right) \\
& +\frac{\lambda_{v}^{5}}{8 \cdot \pi^{2} \cdot w^{2} \cdot\left(2 \cdot w-\lambda_{v}\right)}\left(1+\cos \left(\frac{2 \cdot w \cdot \pi}{\lambda_{v}}\right)\right) \\
& -\frac{\left(2 \cdot w-\lambda_{v}\right)^{2} \cdot \lambda_{v}{ }^{4}}{8 \cdot \pi \cdot w^{3}\left(w-\lambda_{v}\right)} \cdot \sin \left(\frac{w \cdot \pi}{\lambda_{v}}\right) \\
& \left.-\frac{\left(2 \cdot w-\lambda_{v}\right) \cdot\left(2 w^{2}-\lambda_{v} \cdot\left(2 \cdot w-\lambda_{v}\right)\right) \cdot \lambda_{v}{ }^{5}}{8 \cdot \pi^{2} \cdot w^{4}\left(w-\lambda_{v}\right)^{2}} \cdot \cos \left(\frac{w \cdot \pi}{\lambda_{v}}\right)\right] \\
& {\left[\left(P_{v o l}\right)_{V}\right]_{C}=\frac{\left(\left[\left(P_{v o l}\right)_{V}\right]_{c}\right)_{S 1}+\left(\left[\left(P_{v o l}\right)_{V}\right]_{b}\right)_{S 2}}{2}:} \\
& \left(\left[\left(P_{v o l}\right)_{v}\right]_{c}\right)_{S 1}=\frac{4 \times\left(w-\lambda_{v}\right) \times\left[\left(P_{v o l}\left(w-\lambda_{v}\right)\right)_{v}\right]_{a}}{w} \\
& +\frac{2 \times\left(2 \cdot \lambda_{v}-w\right) \times\left[\left(P_{v o l}\left(2 \cdot \lambda_{v}-w\right)\right)_{v}\right]_{a}}{w} \\
& {\left[\left(P_{v o l}\right)_{v}\right]_{d}=} \\
& \frac{2 \times\left[\left(P_{v o l}\left(w=\lambda_{v} / 2\right)\right)_{v}\right]_{a}+\left(\left[\left(P_{v o l}\left(w=3 \lambda_{v} / 2\right)\right)_{v}\right]_{b}\right)_{S 2}}{2} \\
& l \text { : magnet pole length } \\
& w \text { : magnet pole width } \\
& \rho: \text { magnet material resistivity } \\
& \text { e:magnet pole thickness } \\
& \alpha=\frac{l}{w}
\end{aligned}
$$

By observing previous equations, it can be noticed that magnet pole length $l$ can also affect magnet volume losses and it is included in all equations by the ratio $\alpha=l / w$. Nevertheless, in equation (4) the factor $\frac{\alpha^{2}}{\alpha^{2}+1}$ is almost equal to 1 when $\alpha>>1$. Consequently, magnet pole length has no effect on the level of magnet volume losses when it is too long in comparison with magnet width. It is the case in most of non-segmented PM machines where machine length (pole length) is much bigger than its pole width. The same judgment can be accepted for equation (5) where instead of $\alpha$ the factor $\frac{2 \cdot w \cdot \alpha}{\sqrt{\left(2 \cdot w-\lambda_{v}\right) \cdot \lambda_{v}}}$ can be found with $\frac{2 \cdot w}{\sqrt{\left(2 \cdot w-\lambda_{v}\right) \cdot \lambda_{v}}} \geq 1$ within used ranges.

By taking into account last approximation and depending on global equation (3) Fig. 5 shows how magnet volume losses vary with the ratio $\lambda_{v} / w$. It can be seen that MMF parasitic harmonics with relatively long wavelength (according to $w$ ) produce more magnet losses than other harmonics. This explains why sub-harmonics and harmonics close to the fundamental have such a negative effect on magnet volume losses.

In the special case where $\frac{\lambda_{v}}{w}>>1$, magnet volume losses start to be constant as it can be seen in Fig. 5 .

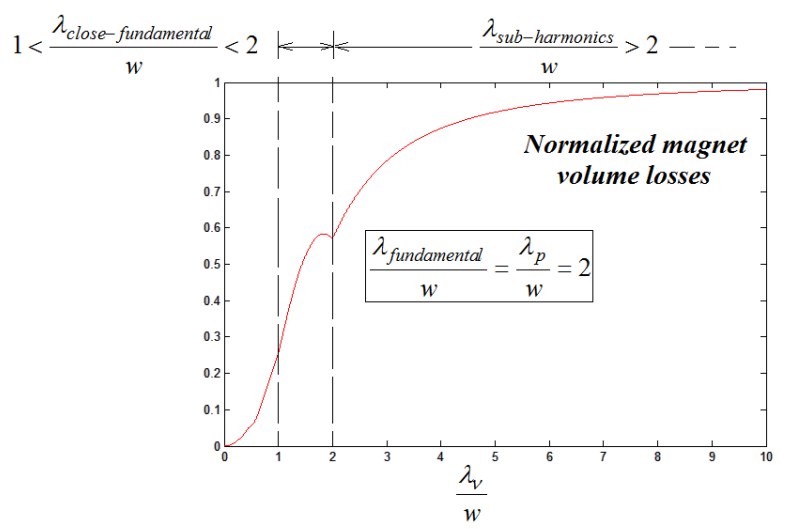

Figure 5. Normalized magnet volume losses as a function of $\lambda_{v} / w$

Moreover, making $\frac{\lambda_{v}}{w} \rightarrow \infty$ in equation (4) gives eddycurrent volume losses in a magnet pole where a spatially homogeneous flux density $B$ is applied (No spatial harmonics) [9]-[11]:

$$
P_{v o l}=\frac{B^{2} \omega^{2}}{32 . \rho} \times \frac{w^{2}}{\left(1+w^{2} / l^{2}\right)}
$$

Considering all rotating sinusoidal flux density distributions resulting from MMF and assuming the additivity of elementary losses, global magnet volume losses model can be written using equations (3) and (2):

$$
\begin{aligned}
& P_{v o l}=\sum_{v \in M M F}\left[\left(P_{v o l}\right)_{v}\right] \\
& \omega_{v}=2 \cdot \pi \cdot f_{\text {rotor }} p\left|\frac{v}{p}-\mathrm{sgn}\right|
\end{aligned}
$$

III. Applying losses model on various Slots/Poles configurations of machines with concentrated winding

In this paragraph the analytical model (6) is used to compare magnet volume losses of various Slots/Poles machine combinations. In order to compare 
configurations which are adapted for automotive application (high speed) the number of poles is limited $\left(p_{\max }=9\right)$. The structures include 3,5 , and 7 phase machines which expand the number of possible configurations and allow comparing their magnet losses according to the phase number [3]. Magnet losses model is applied only on useful combinations whose winding topologies provide high winding factors [10] (first harmonic factor for 3-phase and both first-third harmonic factor for 5, and 7-phase [12][13]).

In this comparison, it is supposed that all combinations are provided with surface-mounted magnets installed on the same rotor of radial flux machine, which means wavelengths $\lambda_{v}$ of parasitic MMF harmonics used in the analytical model can be obtained directly from MMF spatial spectrum in the air gap using equation (1) while more calculations are needed in the case of IPM machines.

TABLE I

Normalized magnet volume losses

\begin{tabular}{|c|c|c|c|c|c|c|c|}
\hline $\begin{array}{c}\text { Slots/ } \\
\text { Poles }\end{array}$ & 4 & 6 & 8 & 10 & 12 & 14 & 16 \\
\hline 6 & 68.19 & - & 198.1 & - & - & - & 138.1 \\
\hline 9 & - & 30.41 & 62.59 & 73.30 & 87.80 & - & - \\
\hline 12 & - & - & 15.97 & 75.26 & - & 68.11 & 49.33 \\
\hline 15 & - & - & - & 10.23 & - & 22.51 & 25.10 \\
\hline 18 & - & - & - & - & 7.113 & 11.91 & 15.07 \\
\hline 21 & - & - & - & - & & 5.23 & - \\
\hline 24 & - & - & - & - & & - & 4.01 \\
\hline
\end{tabular}

3-Phase Configurations

\begin{tabular}{|c|c|c|c|c|c|c|c|c|c|}
\hline $\begin{array}{l}\text { Slots/ } \\
\text { Poles }\end{array}$ & 2 & 4 & 6 & 8 & $\overline{10}$ & 12 & 14 & 16 & 18 \\
\hline 5 & 27.66 & 164.6 & 267 & 262.8 & - & 214.9 & 184.9 & 225.2 & 143.8 \\
\hline 10 & - & 6.231 & 18.30 & 41.54 & - & 66.22 & 71.24 & 65.52 & - \\
\hline 15 & - & - & 2.774 & - & - & 18.52 & 23.33 & 25.43 & 29.34 \\
\hline 20 & - & - & - & 1.562 & - & 4.59 & 26.89 & 9.916 & 26.52 \\
\hline 25 & - & - & - & - & 1 & - & - & - & 5.362 \\
\hline
\end{tabular}

\begin{tabular}{|c|c|c|c|c|c|c|c|}
\hline $\begin{array}{c}\text { Slots/ } \\
\text { Poles }\end{array}$ & 6 & 8 & 10 & 12 & 14 & 16 & 18 \\
\hline 7 & 96.32 & 130.22 & - & - & - & - & - \\
\hline 14 & 3.70 & 8.21 & 15.02 & 24.29 & - & 32.28 & 36.1 \\
\hline 21 & - & - & - & 3.655 & - & 16.58 & 10.828 \\
\hline \multicolumn{8}{|c|}{ 7-Phase Configurations }
\end{tabular}

Double Layer Winding

Single Layer Winding

Since this paper is concerned by the interaction between MMF wavelengths and magnet width, considered machines have relatively long magnet pole comparing with pole width (which is generally the case except in very short structures). This allows avoiding the effect of magnet length and deleting $\alpha$ from analytical model.

The aim of this paper is to compare magnet volume losses generated by winding topologies allowed by different Slots/Poles combinations. Hence, no need to calculate the exact amplitude of flux density $B_{v}$ because it depends on the magnetic structure (rotor, stator, iron...), but $B_{v}$ can be considered as a proportional value to the corresponding MMF harmonic amplitude $F_{V}$.

$$
\begin{aligned}
& B_{v}=A \times F_{v} \\
& A: \text { const of structure } \\
& F_{v}: \text { amplitude of harmonic } v \text { in } M M F \text { spectrum }
\end{aligned}
$$

Therefore, MMF spatial spectrum for all combinations is calculated using their winding topologies where the same linear current density is injected. Then, magnet volume losses can be compared at the same rotor speed taking into account the same structure constant $A$ for all combinations.

Finally, in order to eliminate the mutual factor $\frac{2 \cdot A^{2} \cdot f^{2} \text { rotor }}{\rho}$ between all combinations and harmonics, magnet volume losses are normalized with respect to the lowest value in the case of 5-phase 25/10 as it is shown in table1. In this table three families of combinations can be recognized. A green one with low magnet volume losses in which we can find as example TOYOTA 3-phase generator 12/8, and HONDA 3phase machine 18/12. Moreover, 5-phase combinations belonging to this green family generate the lowest magnet losses among all the others. Combinations from yellow family can be built and run at low and maybe average speeds, while red family configurations will probably lead to magnet demagnetization at average speeds because of heating linked to high magnet losses level. In the case of single layer winding, MMF will be structured with a half number of slot winding. Consequently, more harmful MMF harmonics may appear. The negative effect of single layer winding on magnet losses is another important result given by the analytical model in table. 1 , where all combinations with single layer winding have a relatively high level of magnet losses. Furthermore, in the case of 18/12 3-phase combination calculated magnet volume losses are doubled almost 4 times in the case of single layer winding.

\section{Finite element validation}

In order to validate losses analytical study presented in paragraph 3, 2D finite elements models of some Slots/Poles combinations provided with surfacemounted magnets are built. These models have the same magnetic structure with the same following parameters: rotor radius, efficient length, air gap width, and total magnets volume (see Fig. 6). Hence, direct magnet losses comparison is possible. Moreover, in 
order to ensure a fair comparison the same linear current density is injected in all models, which allows configurations producing the same torque if they have similar winding factors.

Since the used finite elements modeling FEM is $2 \mathrm{D}$, long structures with high ratio $l / w$ are considered. Thus, eddy-current looping back effect (which cannot be taken into account in 2D FEM) becomes weaker.

Fig. 6 illustrates the 5 structures of studied finite elements models, where rotor configurations and stator winding topologies are clearly represented. Calculated MMF spectrums resulting from winding topologies by injecting the same linear current density are illustrated next to their corresponding configurations in Fig. 6.

For the five combinations presented in this figure, magnet volume losses calculated using finite elements models at different rotor speeds are compared with losses given by the analytical model. Fig. 7 represents both losses (analytical and FEM) normalized with respect of losses generated by 20/12 5-phase combination at $1000 \mathrm{rpm}$.

The convergence between FEM and analytical curves in Fig. 7 shows how the proposed analytical model allows comparing effectively different slot/pole combinations of concentrated winding machines.

However, skin effect is not taken into account by the analytical model which may justify the noticed divergence between FEM and analytical curves at high speeds in the case of 15/18 5-phase machine. In such combinations with high number of poles, high frequencies of flux density are applied when rotor speed increases. Consequently, skin depth becomes small comparing with magnet pole dimensions causing the deviation from losses analytical model.

In Fig. 7, the two combinations 14/12 7-phase and 15/18 5-phase generate high level of magnet losses as it is expected in the analytical study because of their MMF sub-harmonic and close to fundamental one (see Fig. 6 (d), (e)).

Finally, for a specific machine structure the constant $A$ in equation (7) can be precisely calculated, which allows getting the different amplitudes of flux density harmonics in magnets. As a result, absolute value of magnet volume losses can be deduced and considered as sufficiently precise in order to use the proposed analytical model in optimization process of PM electrical machines.

\section{Conclusion}

In this paper new analytical model of magnet losses in PM machines with concentrated winding is presented. The effect of different MMF spatial harmonics on magnet losses level is investigated. Furthermore, the interaction between wavelengths of these parasitic harmonics and magnet pole dimensions is studied. Then, analytical model of magnet volume losses is developed and generalized using various submodels in order to cover all possible forms of induced

eddy-current paths configuration.
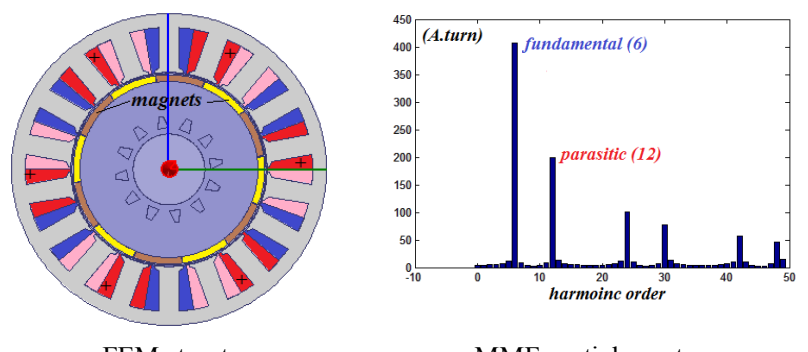

(a): 18/12 3-phase

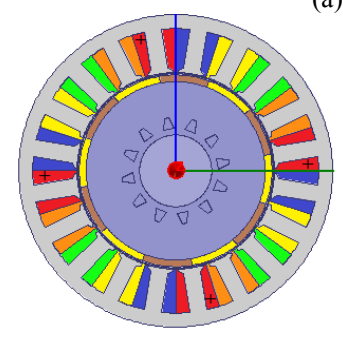

FEM structure

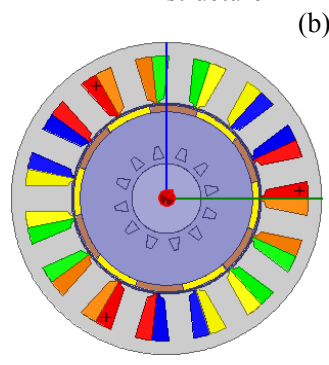

FEM structure

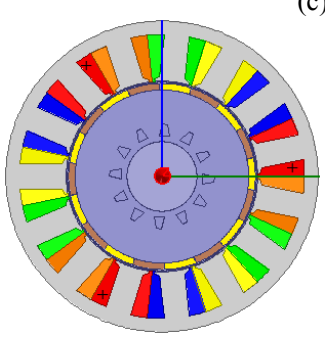

FEM structure

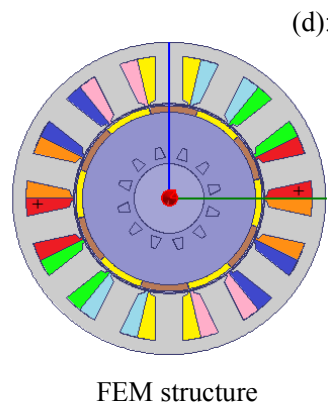

(b): 20/12 5-phase

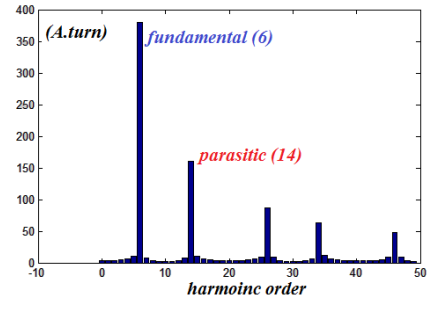

MMF spatial spectrum

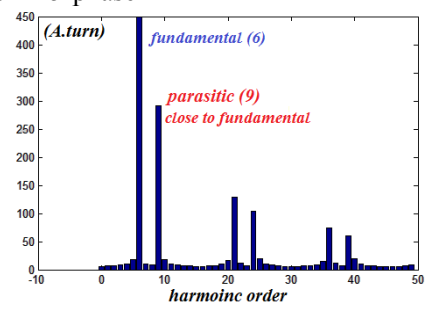

(c): $15 / 12$ 5-phase

MMF spatial spectrum

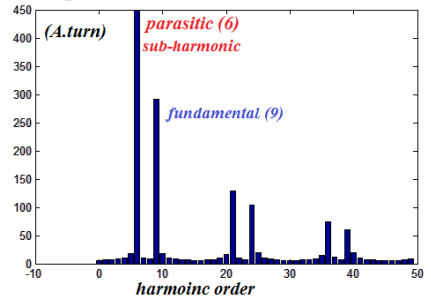

MMF spatial spectrum

d): 15/18 5-phase

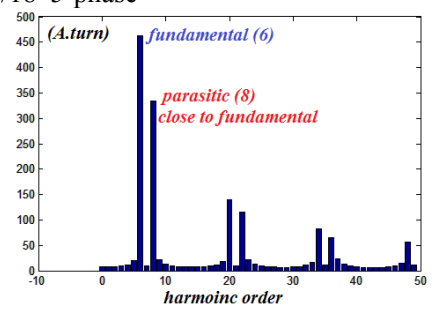

(e): 14/12 7-phase

MMF spatial spectrum

Figure 6. finite elements models and calculated MMF spectrums of five slots/poles combinations

Using this analytical model, magnet volume losses in various combinations of 3,5 , and 7 phase machines are compared between them. 
The results nominate some combinations as good choices for high speed application machines, due to their low level of magnet losses comparing with the others, as in the case of 25/10 and 20/12 5-phase combinations. Finally, finite element models are built in order to validate the analytical equations, where simulation results show a good convergence between analytical and FEM calculations.

Thanks to the presented model, magnet volume losses of any Slots/Poles combination can simply be compared, and scaled to losses of another combination depending only on their winding topologies. Consequently, the model can help designers to compare quickly between many winding configurations of electrical machines, then to early exclude bad choices without the need of long and expensive finite element methods FEM.

Furthermore, by considering a specific machine structure, sufficiently precise value of magnet volume losses can be calculated using the developed model. Therefore, an interesting perspective will be also to use this kind of model in optimization processes, as for example in finding optimal magnet segmentation.

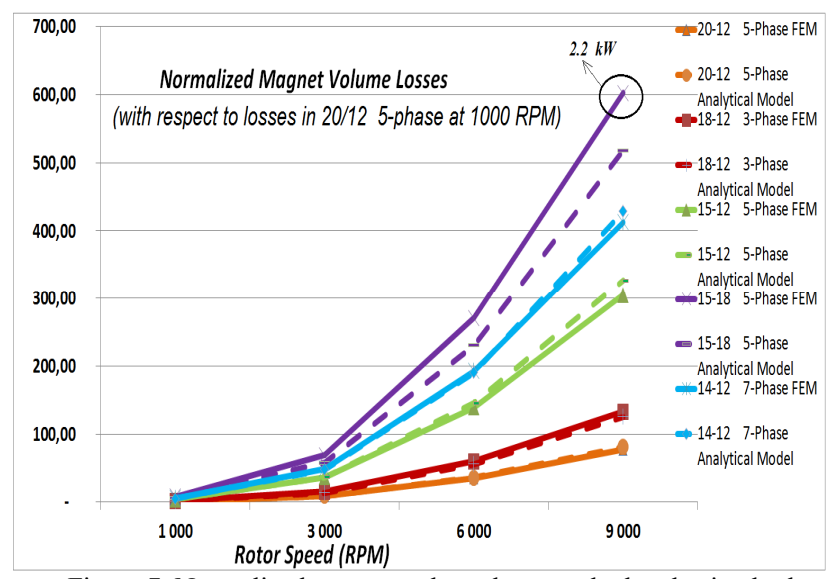

Figure 7. Normalized magnet volume losses calculated using both finite element method and analytical model (equation 12)

\section{ACKNOWLEDGMENT}

Acknowledgment for ADEME funding for MHYGALE project.

\section{REFERENCES}

[1] A.M El-Refaie, "Fractional-Slot Concentrated-Windings Synchronous Permanent Magnet Machines: Opportunities and Challenges", IEEE Trans. on Industrial Electronics, Vol. 57, No. 1, January 2010.

[2] F. Magnussen, H. Lendenmann, "Parasitic Effects in PM Machines with Concentrated Windings," IEEE Trans. on Industry Applications, vol.43, no.5, pp.1223-1232, SeptOct. 2007.

[3] A.M. El-Refaie, M.R. Shah, Ronghai Qu, J.M. Kern, "Effect of Number of Phases on Losses in Conducting Sleeves of Surface PM Machine Rotors Equipped With Fractional-Slot Concentrated Windings," Industry Applications, IEEE Transactions on , vol.44, no.5, pp.1522-1532, Sept.-oct. 2008.

[4] N. Bianchi, E. Fornasiero, "Impact of MMF Space Harmonic on Rotor Losses in Fractional-Slot PermanentMagnet Machines", IEEE Trans. on Energy Conversion, vol.24, no.2, pp.323-328, June 2009.

[5] N. Bianchi, S. Bolognani, E. Fomasiero, "A General Approach to Determine the Rotor Losses in Three-Phase Fractional-Slot PM Machines" Proc of IEMDC 07, IEEE International Electrical Machines and Drives Conference, Turkey, 2007.

[6] D. Ishak, Z.Q. Zhu, D. Howe, "Eddy-current loss in the rotor magnets of permanent-magnet brushless machines having a fractional number of slots per pole", Magnetics, IEEE Transactions on , vol.41, no.9, pp. 2462- 2469, Sept. 2005.

[7] T.J.E. Miller, M.I. McGilp, K.W. Klontz, "Approximate methods for calculating rotor losses in permanent-magnet brushless machines", Electric Machines and Drives Conference, 2009. IEMDC '09. IEEE International, vol., no., pp.1-8, 3-6 May 2009.

[8] J. Pyrhonen, H. Jussila, Y. Alexandrova, P. Rafajdus, J. Nerg, "Harmonic Loss Calculation in Rotor Surface Permanent Magnets ?? New Analytic Approach", Magnetics, IEEE Transactions on, vol.PP, no.99, pp.1, 0 .

[9] Wan-Ying Huang, A. Bettayeb, R. Kaczmarek, J.-C. Vannier, "Optimization of Magnet Segmentation for Reduction of Eddy-Current Losses in Permanent Magnet Synchronous Machine", Energy Conversion, IEEE Transactions on, vol.25, no.2, pp.381-387, June 2010.

[10] B.Aslan, E.Semail, J. Legranger, " Slot/pole Combinations Choice for Concentrated Multiphase Machines dedicated to Mild-Hybrid Applications", International Conference on Industrial Electronics 2011, IECON '11, IEEE International, November 7-10 2011.

[11] A. Bettayeb, X. Jannot, J. Vannier, "Analytical calculation of rotor magnet eddy-current losses for high speed IPMSM," Electrical Machines (ICEM), 2010 XIX International Conference on , vol., no., pp.1-6, 6-8 Sept. 2010.

[12] E.Levi, "Multiphase electric machines for variable-speed applications," IEEE Trans. on Industrial Electronics, vol. 55, no. 5, 2008, pp. 1893-1909.

[13] F. Scuiller, J.-F. Charpentier, E. Semail, S. Clenet, "Comparison of two 5-phase Permanent Magnet machine winding configurations. Application on naval propulsion specifications" Electric Machines \& Drives Conference, 2007. IEMDC '07. IEEE International, vol.1, no., pp.3439, 3-5 May 2007. 